\title{
Visibilidade e engajamento público na web 2.0: um estudo altmétrico a partir dos artigos publicados na Scientific Data
}

\author{
Janinne Barcelos \\ Doutoranda, Universidade de Brasília, Brasília, DF, Brasil; \\ janbarcelos@hotmail.com \\ João de Melo Maricato \\ Doutor, Universidade de Brasília. Brasília, DF, Brasil; \\ jmmaricato@gmail.com
}

\begin{abstract}
Resumo: A Web 2.0 tem causado impactos na comunicação científica. O uso das mídias sociais tem sido utilizado de maneira crescente para compartilhar produtos científicos, havendo diferentes dinâmicas de visibilidade e engajamento público. Nesse contexto, a pesquisa busca compreender aspectos da visibilidade e engajamento na Web 2.0, a partir de artigos publicados pela revista Scientific Data, entre os anos de 2014 e 2019, utilizando-se de métodos e técnicas altmétricas. Dessa forma, são identificadas e analisadas as mídias em que esses documentos receberam atenção; os usuários responsáveis por fazer a primeira postagem de divulgação do artigo nas mídias, além das relações entre as menções em mídias sociais e o possível incremento na contagem de citações. Constatou-se que o Twitter foi a mídia mais utilizada para a divulgação dos artigos; que os pesquisadores autores não são os principais responsáveis pela primeira menção dos artigos nas mídias analisadas; e, que não existe uma nítida relação de causa e efeito entre indicadores de citação e menção. Foram vislumbrados aspectos relevantes sobre o entendimento da visibilidade e do engajamento público com a produção acadêmica nas mídias sociais, auxiliando também na compreensão das dinâmicas e características relacionadas aos indicadores altmétricos.
\end{abstract}

Palavras-chave: Visibilidade. Engajamento público. Mídias sociais. Altmetria.

\section{Introdução}

Atualmente, mais da metade da população mundial acessa a Internet. Não só o número de pessoas utilizando a rede cresceu, como o tempo on-line gasto por elas também aumentou. Hoje um usuário passa cerca de seis horas por dia navegando em bits. Segundo Kemp (2019), a cada segundo são registrados 11 
novos perfis nas mídias sociais, atingindo a impressionante marca de 3,5 bilhões de usuários, em julho de 2019 (um quarto de bilhão a mais que no ano anterior). Ou seja, são mais de $46 \%$ da população total do mundo acessando diariamente o Twitter, o Facebook, o Mendeley ou qualquer outra rede escolhida.

Com efeito, desde que "a Internet passou a ser o centro do novo paradigma sociotécnico, todo o ambiente midiático contemporâneo foi modificado por processos progressivos de digitalização, globalização e convergência" (MIURA, 2012, p. 9). Esse amplo acesso à rede mundial de computadores, com destaque para a Web 2.0, tem impulsionado inúmeras mudanças no paradigma da comunicação científica. Para Filippo e Sanz-Casado (2018), o advento da Web 2.0 trouxe alterações significativas que melhoraram a comunicação e a colaboração entre os acadêmicos, assim como sua interação com o público geral.

Um exemplo do impacto da Web 2.0 na comunicação científica é o uso das mídias sociais por muitos pesquisadores que desejam compartilhar seus conhecimentos e experiências "abertamente" na rede. É crescente o número de cientistas que apresentam trabalhos ao público via blogs, wikis e redes sociais (IAMARINO, 2018). Esse movimento, ao qual a academia deu o nome de Ciência 2.0, propõe que, uma vez abertas a todos, as pesquisas

$$
\begin{aligned}
& \text { podem receber críticas e sugestões, além de conduzir à partilha de } \\
& \text { dados e ideias, a correções e melhorias, preenchendo lacunas no } \\
& \text { diálogo entre pares, para criar novos conhecimentos, passível de } \\
& \text { tornar a ciência mais produtiva. (MIURA, 2012, p. 10). }
\end{aligned}
$$

Diante dessas mudanças, muito tem-se argumentado sobre o uso das mídias sociais (canais informais) para publicação e divulgação de resultados de pesquisas acadêmicas. Entre as discussões mais recorrentes na literatura nacional e internacional, estão: 1) a legitimidade das informações publicadas nestas mídias (visto que se tratam de canais de autoria própria, podendo ou não apresentar a revisão feita por pares); 2) a ampliação dos debates com participação e engajamento do público geral; 3) a possibilidade de rastrear e avaliar novos tipos de impacto das pesquisas; e 4) a visibilidade mediada na Web 2.0, tanto das pesquisas quanto dos pesquisadores (PRIEM; 
HEMMINGER, 2010; BIK; GOLDSTEIN, 2013; FILIPPO; SANZ-CASADO, 2018).

Com vistas para este cenário, neste estudo busca-se compreender aspectos da visibilidade e engajamento na Web 2.0, a partir dos artigos científicos da Scientific Data (revista cujo escopo concentra-se em áreas relacionadas à Ciência da Computação; Educação; Sistemas de Informação; Estatística e Probabilidade; Biblioteconomia e Ciência da Informação). Para tanto, apoia-se em indicadores altmétricos para identificar e analisar as mídias sociais em que esses documentos receberam atenção; os usuários responsáveis por fazer a primeira postagem de divulgação do artigo em tais mídias e as relações entre as menções e o possível incremento na contagem de citações.

Importa ressaltar que para evitar confusões entre a linguagem utilizada nos estudos métricos tradicionais (principalmente, Bibliometria, Cientometria e Webometria) e na Altmetria tomou-se o cuidado de distinguir os termos "publicação" e "menção" entendidos, respectivamente, como: a) disseminação formalizada de uma produção científica para o público seja sob a forma de um artigo, um livro ou um verbete de enciclopédia (CUNHA; CAVALCANTI, 2008); b) “qualquer alusão ou referência feita à uma produção científica nas mídias sociais, incluindo seu compartilhamento, publicação, tweets, retweets, postagens, curtidas, comentários" (BARCELOS; MARICATO, 2017).

\section{Visibilidade e engajamento público na web 2.0}

A visibilidade é uma característica intrínseca à comunicação científica. Como explicam Oliveira e Grácio (2012, p. 100), a visibilidade "representa a capacidade que uma fonte de informação possui de influenciar seu público-alvo, bem como de ser acessada em resposta a uma demanda de informação". Na comunicação científica feita através de canais formais, os periódicos ainda são considerados meio privilegiado para o alcance de visibilidade e prestígio dos pesquisadores (MUELLER, 2000). Contudo, o alinhamento entre comunicação científica e novas tecnologias de comunicação indica que a divulgação das pesquisas será gerida de modo mais aberto, a fim de que ela chegue até um público mais amplo e diversificado (BIK; GOLDSTEIN, 2013). 
Sobretudo, com a emergência da Web 2.0, nota-se que os pesquisadores têm se apropriado das mídias sociais para se comunicar com pessoas interessadas em pesquisas (sejam elas seus pares, ou não). Segundo Barata (2016), torna-se cada vez mais comum o uso de mídias sociais para fazer comentários sobre temas pertinentes à uma área de investigação, sobre atividades cotidianas da pesquisa e produções acadêmicas diversas. Atualmente,

\begin{abstract}
muitos sites de compartilhamento de conteúdo, como fóruns, blogs e redes sociais (incluindo o Facebook e o Twitter), não só provaram ser muito populares entre o público em geral, mas também seduziram membros da comunidade científica, dando origem à chamada "web social acadêmica". Este novo espaço permite aos pesquisadores compartilhar e validar seus projetos por meio de ferramentas conectadas ao ambiente acadêmico, como softwares de gerenciamento de referências (Mendeley, CiteULike), redes profissionais (ResearchGate, ScienceOpen) e aplicativos de identidade digital (ResearcherID da Web of Science ou ORCID). (FILIPPO; SANZ-CASADO, 2018, on-line, tradução nossa).
\end{abstract}

Dentro da academia, tal comportamento é reforçado pelo movimento Open Access (OA) que faz ampliar a comunicação informal em torno de publicações e repositórios virtuais. "Provas disso podem ser vistas nos espaços acadêmicos online que começaram a crescer e prosperar no início dos anos 2000, após a articulação do acesso aberto, incluindo a Public Library of Science e arXiv" (ROEMER; BORCHARDT, 2015, p. 7, tradução nossa). Outros exemplos de mídias, como PLOS ONE, ResearchGate, CiteSearch e PubMed, também endossam a ideia de acesso aberto, enquanto rastreiam as interações informais entre pesquisadores e usuários.

Para Wilcox (2011), o uso das mídias sociais é uma tendência mundial e, portanto, se os cientistas não estão se utilizando destas ferramentas, eles simplesmente não estão se comunicando com a maioria da população. Embora alguns pesquisadores ainda estigmatizem o uso das mídias sociais como desperdício de tempo ou distração dos objetivos da pesquisa, "um número crescente de evidências sugere que a visibilidade pública e a conversa construtiva em redes de mídia social podem ser benéficas para os cientistas, impactando a pesquisa de maneira relevante" (BIK; GOLDSTEIN, 2013, p. 3, tradução nossa). Ou seja, se bem gerenciadas, estas ferramentas digitais podem ser apropriadas como um novo tipo de marketing científico", "projetando 
referees e autores, atribuindo-lhes prestígio e a visibilidade tão almejada" (BOMFÁ et al., 2009, p. 203).

Para além da visibilidade mediada nas mídias sociais, destaca-se o fato das conversas on-line oferecem aos produtores da informação científica a possibilidade de falar "diretamente para um público, de aparecer diante dele em carne e osso como um ser humano com o qual seria possível criar empatia e até simpatizar, dirigir-se a ele não como público, mas como amigo" (THOMPSON, 2008, p. 24). Ou seja, destaca-se o fato da comunicação (informal) da ciência nas mídias sociais possibilitar novas formas de engajamento, participação e colaboração pública com as pesquisas.

Neste sentido, Bik e Goldstein (2013) acreditam que os pesquisadores podem se beneficiar das mídias sociais não apenas para o aumento de visibilidade, como, também, para promover amplos diálogos com o público geral, estimulando um sistema de produção científica que esteja em sintonia com a sociedade. Tal pensamento está profundamente alinhado com pensadores como Ziman (1979), Oliveira (2002), Massarani (2012), Barcelos, Macêdo e Maricato (2020) que acreditam que a ciência tem importante papel na promoção social e econômica de um país, indo muito além de produzir postulados e tornálos visíveis.

A possibilidade de estimular a discussão pública em torno de pesquisas finalizadas ou em andamento tem sido um dos pontos de argumentação mais debatidos pelos defensores do uso das mídias sociais. Isto porque, se por um lado a divulgação científica feita por meio da criação de zoológicos, planetários e museus de história natural ou mesmo da produção de sites, revistas, filmes, programas de rádio e televisão, dentre outros, aproxima a ciência do público em geral, por outro, observa-se que este modelo de divulgação privilegia pesquisas já maduras e consolidadas (LEWENSTEIN, 2003). Essa característica leva a problemas no fluxo da comunicação científica como a marginalização de pesquisas em fases iniciais e a subestimação de pesquisadores que se dedicam ao estudo de objetos que não estão em voga (ALPERIN, 2013).

Além disso, a divulgação científica feita nos canais supracitados, por vezes, resulta num fluxo unilateral de transmissão das informações (do produtor para o receptor), apresentando os resultados de pesquisa como se fossem 
estáticos/definitivos e, principalmente, desvalorizando o papel do público nas questões relacionadas à ciência. Entretanto, é preciso evidenciar o caráter dinâmico e controverso da ciência, ampliar o espaço para discussão, conceder ao público um papel protagonista nos diálogos sobre C\&T e oportunizar seu engajamento (MASSARANI, 2012).

Para pensadores como Wilcox (2011), Bik e Goldstein (2013) e Barata (2016) é justamente essa possibilidade que o uso das mídias sociais oportuniza: uma solução adicional na produção e divulgação científica para cultivar o relacionamento com o público. Pois, além de recursos tradicionais de navegação, as mídias sociais oferecem espaço para interatividade, envolvimento e influência em vários níveis, permitindo a postagem de "resultados experimentais ou finais, matérias, novas teorias, reivindicações de descoberta e de projetos para que outros possam ver e comentar" (ARAÚJO, 2015, p. 68). Mas para esse tipo de interação aconteça, basta que a pesquisa esteja on-line?

O primeiro ponto a ser considerado é que existe uma diferença entre "estar on-line" e ser visível on-line. A partir dos ensinamentos de Thompson (2008, p. 37), pode-se dizer que a visibilidade pelas mídias implica em “conseguir um tipo de presença ou de reconhecimento no âmbito público que pode servir para chamar a atenção para a situação de uma pessoa ou para avançar a causa de alguém”. Isto é, a visibilidade pelas mídias não é fruto apenas do meio pelo qual as informações são levadas ao conhecimento dos outros, mas, principalmente, pelas formas distintas de interação do público com o que é veiculado, nas suas diversas possibilidades de engajamento.

Com variável atrelada às múltiplas facetas do engajamento público, estar visível nas mídias sociais pode significar, para uma pesquisa ou para um pesquisador, sua popularidade em meio às redes virtuais de compartilhamento na web 2.0. É sob esta perspectiva que a Altmetria tem discutido, desde 2010, as razões pelas quais um artigo ou assunto específico ganha visibilidade na internet, utilizando-se de ferramentas que medem a atenção on-line em torno da publicação e classificando com alta pontuação altmétrica aquelas pesquisas mais mencionadas, comentadas, compartilhadas ou baixadas (KOLAHI, et al., 2020).

Dessa forma, seria razoável deduzir, que a nova visibilidade das publicações científicas pode ser verificada, a partir do nível de engajamento 
gerado em cada mídia, considerando não só em quais mídias o documento foi mencionado, mas principalmente se o primeiro post foi feito por outros usuários da rede ou pelos próprios pesquisadores, numa tentativa de autopromoção. Assim como, se a reverberação em mídias sociais incrementa, de certa maneira, o número de citações que um artigo recebe. É o que se analisa nas próximas seções.

\section{Procedimentos metodológicos}

Trata-se de um estudo empírico-analítico, cujo tipo de abordagem pode ser considerado qualiquantitativo, uma vez que seu objetivo é investigar características de visibilidade e engajamento público, a partir dos artigos publicados na Scientific Data - revista científica de acesso aberto, revisada por pares e publicada desde 2014 pelo Nature Publishing Group. De acordo com o SCImago Journal Rank (SJR), divulgado em dezembro de 2019, a Scientific Data é a revista com maior quantidade de menções na Web 2.0, quando comparada às demais revistas avaliadas pelo $\mathrm{SJR}^{2}$, tendo $98 \%$ dos artigos mencionados em pelo menos uma mídia social.

A análise está apoiada em técnicas e princípios da Altmetria. Nova nos estudos métricos da informação, a Altmetria busca medir o impacto social da produção científica na Web 2.0, por meio do número de compartilhamentos, menções, visualizações e downloads gerados por uma determinada pesquisa em sites e redes sociais. Na Altmetria, o comportamento do leitor on-line, as interações com o conteúdo e as referências feitas em mídias sociais são todos interpretados como relevantes indicadores de visibilidade e engajamento público com os resultados de pesquisa (PRIEM; HEMMINGER, 2010; NASSI-CALÓ, 2015; NATIONAL INFORMATION STANDARDS ORGANIZATION, 2016).

A Figura 1 esboça o diagrama da metodologia utilizada para a seleção do universo de pesquisa.

Figura 1 - Diagrama da metodologia empregada para seleção do universo para estudo altmétrico da visibilidade e engajamento público, a partir dos artigos da Scientific Data. 


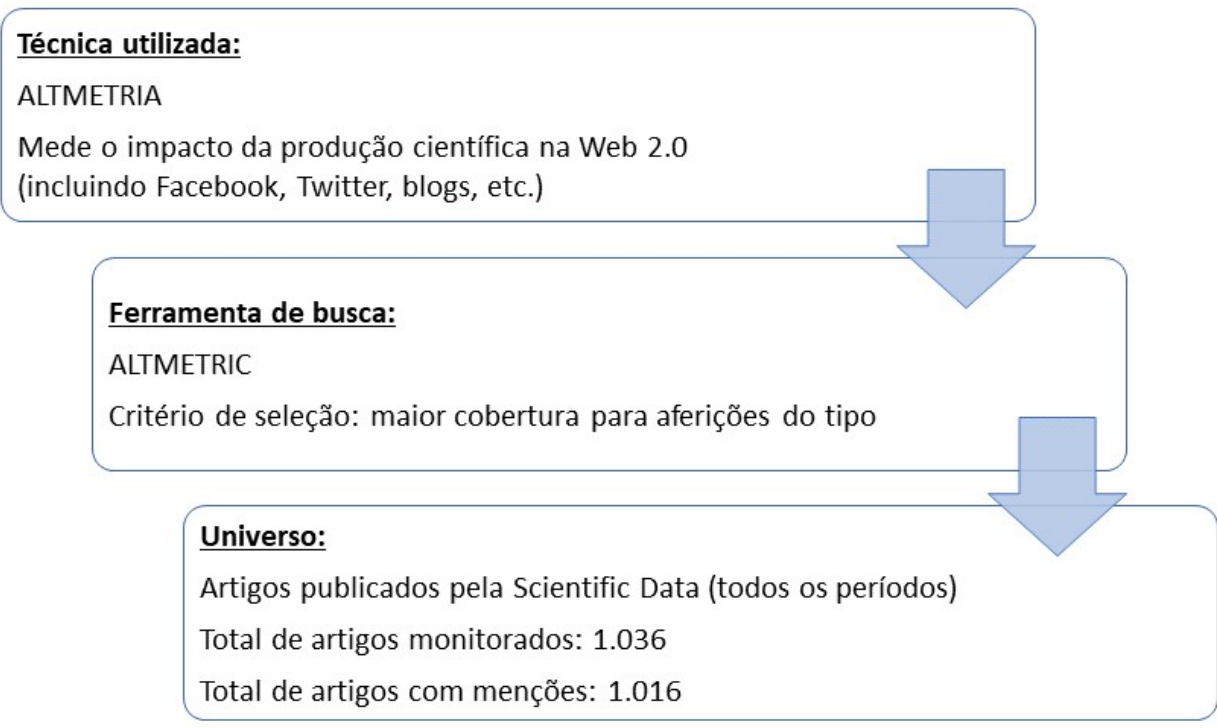

Fonte: Dados da pesquisa (2019).

Para o levantamento de dados utilizou-se a Altmetric (www.altmetric.com), por ser atualmente considerada a plataforma com maior cobertura para aferições altmétricas (ROEMER; BORCHARDT, 2015). Para os fins deste trabalho, utilizou-se a versão gratuita do Altmetric Explorer, cujo acesso é permitido para bibliotecários e pesquisadores, desde que um acordo de compartilhamento dos dados seja assinado e respeitado.

Assim, o universo deste estudo compreende 1.036 artigos publicados pela Scientific Data e monitorados pela Altmetric, dentre os quais, 1.016 (98\%) foram mencionados pelo menos uma vez em mídias sociais. A busca deu-se no dia 03 de dezembro de 2019, utilizando-se a senha disponibilizada pela empresa (Explorer Login), na interface de busca avançada com o nome da revista (Scientific Data) no campo “Journal or Collection”, em todos os períodos (2014 a 2019).

Para as análises de abordagem qualitativa, que extrapolam o conjunto de dados fornecidos pela Altmetric, foi necessário isolar variáveis e realizar buscas manuais, alterando as técnicas de acordo com o aspecto investigado. O Quadro 1 expõe os procedimentos utilizados em cada amostragem.

Quadro 1 - Procedimentos utilizados para seleção de amostras e análise de artigos da Scientific Data em função dos objetivos (2014 a 2019).

\begin{tabular}{|l|l|l|}
\hline Objetivo & Amostra & Procedimentos \\
\hline
\end{tabular}


Janinne Barcelos e João de Melo Maricato

\begin{tabular}{|c|c|c|c|}
\hline $\begin{array}{l}A \\
m \\
o \\
s \\
t \\
r \\
a\end{array}$ & $\begin{array}{l}\text { Verificar se o } \\
\text { primeiro post } \\
\text { foi feito por } \\
\text { outros } \\
\text { usuários da } \\
\text { rede ou pelos } \\
\text { próprios } \\
\text { pesquisadores } \\
\text { (autores/coaut } \\
\text { ores) }\end{array}$ & $\begin{array}{l}\text { 10 quartil } \\
\text { (ranking } \\
\text { baseado no } \\
\text { Altmetric } \\
\text { Attention } \\
\text { Score, com } \\
258 \text { artigos) }\end{array}$ & $\begin{array}{l}\text { 10) coleta manual de data e hora da primeira } \\
\text { postagem, por meio de visita à página que publicou } \\
\text { cada menção; } \\
\text { 2ํ) verificação manual da identidade da autoria, } \\
\text { por meio de acesso ao perfil do usuário que fez a } \\
\text { primeira postagem; } \\
\text { 3ㅇ) identificação manual do tipo de autoria, } \\
\text { confrontando os nomes dos autores/coautores e } \\
\text { revista, com os nomes dos usuários; } \\
\text { 4o) a partir dos resultados da 3ạ etapa, os autores } \\
\text { categorizam os tipos de autoria em: "Pesquisador } \\
\text { Autor" (menção feita por um dos pesquisadores do } \\
\text { artigo); "Revista" (menção feita pela própria } \\
\text { Scientific Data) e "Outros usuários” (menção feita } \\
\text { por outros atores, que não pesquisadores do } \\
\text { artigo ou a Scientific Data, incluindo divulgadores, } \\
\text { instituições, empresas e público interessado). }\end{array}$ \\
\hline $\begin{array}{l}\text { A } \\
\mathrm{m} \\
\mathrm{o} \\
\mathrm{s} \\
\mathrm{t} \\
\mathrm{r} \\
\mathrm{a}\end{array}$ & $\begin{array}{l}\text { Verificar } \\
\text { relações entre } \\
\text { visibilidade } \\
\text { nas mídias } \\
\text { sociais e o } \\
\text { possível } \\
\text { incremento na } \\
\text { contagem de } \\
\text { citações }\end{array}$ & $\begin{array}{c}\text { Os dez artigos } \\
\text { mais citados } \\
\text { em cada ano } \\
\text { (40 artigos, no } \\
\text { total) }\end{array}$ & $\begin{array}{l}\text { 10) Separação dos artigos por anos de publicação } \\
\text { considerados cheios: 2015, 2016, 2017, } 2018 \\
\text { (evidencia-se que a revista começou a publicar no } \\
\text { meio do ano de } 2014 \text { e que a coleta para este } \\
\text { estudo foi realizada antes do fim de 2019); } \\
\text { 20) Isolamento dos artigos por ano de publicação } \\
\text { (considerando que os artigos precisam de um } \\
\text { tempo de exposição similar, a análise foi feita ano a } \\
\text { ano); } \\
\text { 3o) Classificação ordenada dos artigos pelo maior } \\
\text { número de citações (segundo o monitoramento da } \\
\text { Altmetric). }\end{array}$ \\
\hline
\end{tabular}

Fonte: Dados da pesquisa (2019).

\subsection{Limitações da pesquisa}

O estudo se limitou a analisar artigos recuperados pela Altmetric, não se tratando, portanto, de um estudo exaustivo. Embora esta seja uma plataforma de ampla cobertura, reconhece-se que pesquisas igualmente relevantes podem não ter sido rastreadas por falta de identificadores persistentes nas menções feitas em mídias sociais e, portanto, não coletadas pela Altmetric, que rastreia: DOI, IDs do PubMed, IDs do Arxiv e Handles.

Alguns artigos publicados em 2019 podem não ter sido selecionados na análise, já que a coleta foi realizada no final daquele ano e algumas bases levam semanas (ou até meses) para atualizarem seus bancos de dados. Além disso, notou-se algumas discrepâncias na Altmetric em relação à data da publicação dos artigos e a data de sua menção nas fontes indexadas (por exemplo, erros ocasionais onde as menções de blogs e sites de notícias apareceram antes 
mesmo da publicação do artigo no periódico). Tais incoerências foram corrigidas manualmente.

Ao categorizar os posts que não foram feitos pelo "Pesquisador Autor" ou pela "Revista" como "Outros usuários" objetiva-se apenas investigar qual destes grupos faz o primeiro post sobre a pesquisa nas mídias sociais a fim de compreender, por exemplo, se esta ação não se trata de uma "automenção" ou autopromoção. Não se pretende inferir que o engajamento se dá por intermédio do que se chamaria de "público em geral" ou "público leigo". Para isso, seriam necessárias pesquisas mais aprofundadas, com este fim específico.

\section{Apresentação e análise dos dados}

Entre 2014 (ano em que Scientific Data teve início) e 2019 foram monitorados 1.036 artigos, dos quais 1.016 (98\%) receberam atenção nas mídias sociais indexadas pela Altmetric. No total, estes artigos foram mencionados 33.844 vezes em sites de notícias, blogs, plataformas de revisão por pares (F1000 e Peer Reviews), Facebook, Twitter, Google+, Wikipédia, Reddit ${ }^{3}$, documentos de Políticas Públicas (PP's), Q\&A ${ }^{4}$, Vídeos e documentos de patentes.

Para esta análise considerou-se apenas as mídias sociais que fazem parte do cálculo do altmetric score, excluindo, portanto, os dados sobre leitores no Mendeley. Na Tabela 1, é possível observar que, entre os tipos de mídia, as redes sociais computaram atenção mais expressiva. No total, as redes sociais representam mais de $95 \%$ de todas as referências de visibilidade e engajamento público do universo em questão.

$\mathrm{Na}$ categoria redes sociais, o Twitter foi a mídia mais utilizada para a divulgação dos artigos sob análise. Dos 1.036 artigos, 1.012 (97,7\%) foram tuitados pelo menos uma vez por usuários em 141 países diferentes. Uma das possíveis razões para a preferência por esta mídia - também notada nas pesquisas de Erfanmanesh e Alperin (2017) - pode ser o fato de o Twitter estar mais focado na partilha de opinião e informação, ao invés de uma interação social recíproca. Como sintetizam Huberman, Romero e Wu (2008), ao contrário do Facebook, o foco do Twitter está menos em sobre "quem você é" e mais em sobre "o que você tem a dizer". Portanto, a publicação da URL de um artigo por usuários do Twitter pode ser considerada uma forma de visibilidade 
Janinne Barcelos e João de Melo Maricato

da referida produção científica, com potencial para gerar engajamento do público, que poderá clicar na URL, realizar a leitura e retweetar a postagem.

Tabela 1 - Tipos de mídia em que artigos da Scientific Data foram mencionados (2014 a 2019).

\begin{tabular}{|c|c|c|c|}
\hline TIPOS DE MÍDIA & MÍDIAS & № DE MENÇÕES & $\%$ \\
\hline \multirow[t]{5}{*}{ Redes sociais } & & 32424 & $95,80 \%$ \\
\hline & Twitter & 31598 & $93,36 \%$ \\
\hline & Facebook & 603 & $1,78 \%$ \\
\hline & Google + & 178 & $0,53 \%$ \\
\hline & Reddit & 45 & $0,13 \%$ \\
\hline \multirow[t]{3}{*}{ Blogs e Notícias } & & 1276 & $3,77 \%$ \\
\hline & Notícias & 827 & $2,44 \%$ \\
\hline & Blog & 449 & $1,33 \%$ \\
\hline \multirow[t]{4}{*}{ Outras fontes } & & 101 & $0,30 \%$ \\
\hline & Wikipedia & 85 & $0,25 \%$ \\
\hline & $Q \& A$ & 10 & $0,03 \%$ \\
\hline & Vídeo & 6 & $0,02 \%$ \\
\hline \multirow[t]{3}{*}{ Políticas e Patentes } & & 32 & $0,09 \%$ \\
\hline & Doc. Políticas Públicas & 31 & $0,09 \%$ \\
\hline & Patentes & 1 & $0,00 \%$ \\
\hline \multirow[t]{3}{*}{ Revisão por pares } & & 11 & $0,03 \%$ \\
\hline & F1000 & 8 & $0,02 \%$ \\
\hline & Peer Review & 3 & $0,01 \%$ \\
\hline & 「AL & 33844 & $100 \%$ \\
\hline
\end{tabular}

Fonte: Dados da pesquisa (2019).

Como o Facebook tem cinco vezes mais usuários ativos que o Twitter (hoje com 330 milhões), para Erfanmanesh e Alperin (2017) é importante notar que provavelmente o número de menções do Facebook seja maior do que o recuperado $(1,78 \%)$. Uma das razões dessa afirmação deve-se ao fato de que, segundo a Altmetric, a plataforma rastreia apenas mensagens de páginas públicas - excluindo, por exemplo, links em grupos fechados. Outras redes sociais tiveram desempenho insignificante. Conforme a Tabela 1, juntos, o 
Reddit e o Google+ (que teve as contas pessoais desativadas em abril de 2019) representam apenas $0,1 \%$ do número de menções. As redes sociais Linkedin, Weibo e Syllabi não foram incluídas na Tabela 1, tendo em vista que nenhuma menção aos artigos foi observada. Quanto ao Linkedin e ao Weibo, cabe ressaltar que ambos não estão rastreáveis desde 2015, em razão de suas políticas de privacidade, mas que os dados históricos anteriores a este período foram mantidos pela Altmetric.

Ao analisar o número de menções em cada uma das mídias (Tabela 1), ficou evidente que o Twitter possui maior engajamento do público, contabilizando 31.598 (93,36\%) menções, mas destacou-se também expressiva quantidade de menções em sites de notícias (827; 2,44\%) e em blogs (449; $1,33 \%$ ) - mídias cujo tipo de conteúdo conta com textos mais extensos e elaborados e, portanto, mais demorados de serem publicados do que mensagens no Twitter, que limita até 280 caracteres para cada post. A contribuição dessas mídias aumentou ano a ano a visibilidade dos artigos, com média de crescimento de Notícias de 55,76\% e de posts no Twitter, blogs e Facebook, de 53,99\%, $22,07 \%$ e 6,44\%, respectivamente (ver Figura 2).

Durante a análise do universo, notou-se também que a divulgação dos artigos da Scientific Data se inicia, na maioria das vezes $(88,33 \%)$, por meio de um tweet. Mesmo nos casos em que a URL do artigo é compartilhada em diversas mídias, a maioria dos usuários posta primeiro no Twitter e depois no Facebook, blogs, sites de notícias etc. Esse comportamento pode estar associado ao fato de o Twitter ser conhecido como lugar para disseminar informações compactadas com mais imediatismo.

Figura 2 - Crescimento anual de menções dos artigos da Scientific Data, por mídia digital (2014 a 2019). 


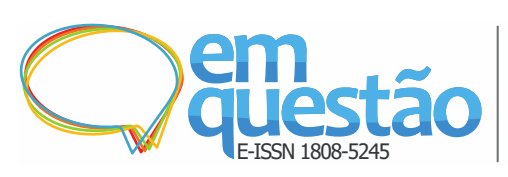

Twitter
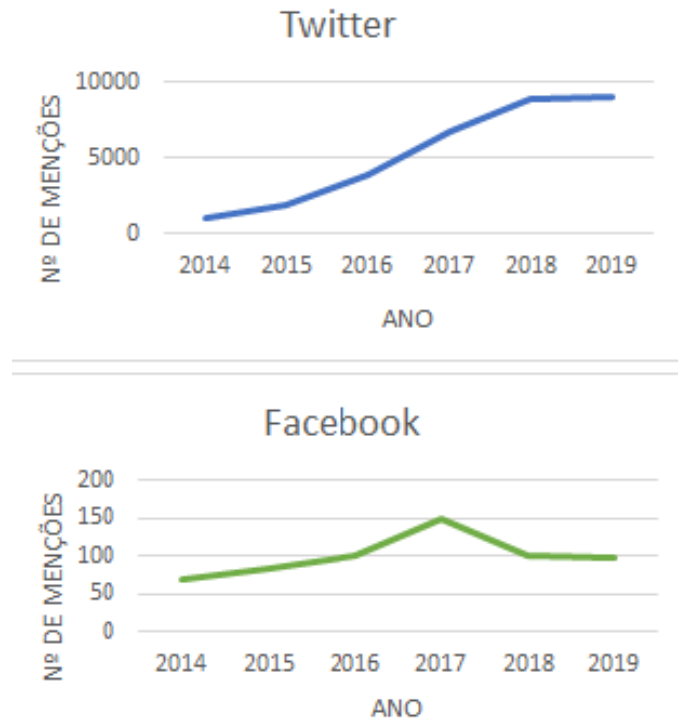

Janinne Barcelos e João de Melo Maricato

Fonte: Dados da pesquisa (2019).

Notícias
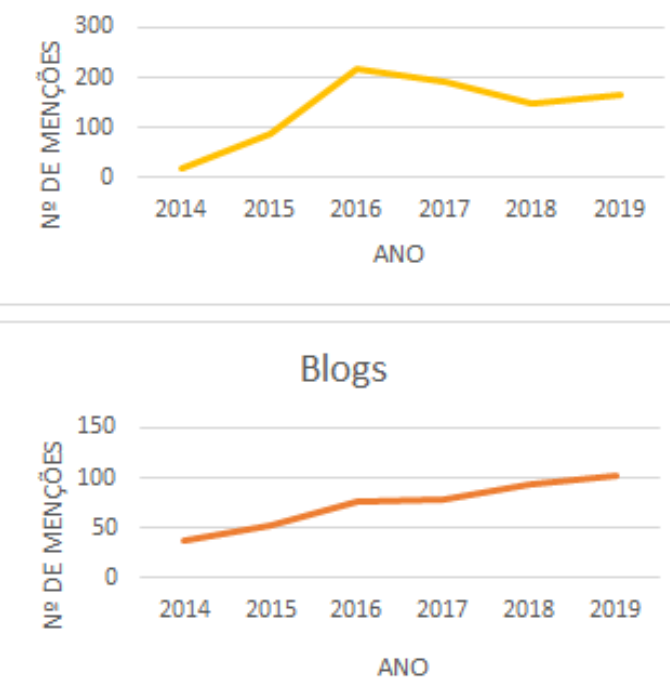

Blogs (1)

Segundo Lee (2019), muitos cientistas que desejam dar visibilidade aos trabalhos utilizam o Twitter porque a rede social permite que públicos diferenciados encontrem novas pesquisas, sem precisar procurá-las em sites de laboratórios e universidades. Além disso, o Twitter é visto como "porta de entrada" para os membros do público que desejam contato direto com os pesquisadores (LEE, 2019).

\subsection{Perfil do usuário da primeira postagem}

Para verificar quem foi o usuário responsável pela primeira postagem de divulgação do artigo nas mídias sociais, extraiu-se (Amostra 1) o primeiro quartil (258 artigos) e buscou-se identificar os autores da primeira menção, separando-os em três categorias: "Pesquisador Autor", para menção feita por um dos autores do artigo; "Revista", para menção feita pela própria Scientific Data e “Outros usuários”, para menção feita por outros atores das mídias sociais que incluem divulgadores, instituições, empresas e público interessado (Tabela 2). Os posts dos artigos recuperados pela Altmetric foram confrontados manualmente a partir da data e hora de sua publicação em cada mídia. Os posts cuja data ou hora não foi identificada $(5,45 \%)$ foram descartados.

Tabela 2 - Autoria da primeira menção aos artigos da Scientific Data na Web 2.0 (2014-2019). 


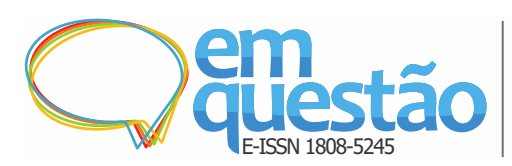

Visibilidade e engajamento público na web 2.0: um estudo altmétrico a partir dos artigos publicados na

Scientific Data

Janinne Barcelos e João de Melo Maricato

\begin{tabular}{|c|c|c|c|c|c|c|c|c|}
\hline \multirow{2}{*}{$\begin{array}{l}\text { MÍDIAS/ } \\
\text { PERFIL }\end{array}$} & \multicolumn{2}{|c|}{ Pesquisador autor } & \multicolumn{2}{|c|}{ Revista } & \multicolumn{2}{|c|}{ Outros usuários } & \multicolumn{2}{|c|}{ Postagens } \\
\hline & Qtd & $\%$ & Qtd & $\%$ & Qtd & $\%$ & Qtd & $\%$ \\
\hline Twitter & 45 & $18,52 \%$ & 81 & $33,33 \%$ & 101 & $41,56 \%$ & 227 & $93,42 \%$ \\
\hline Facebook & 0 & $0,00 \%$ & 7 & $2,88 \%$ & 1 & $0,41 \%$ & 8 & $3,29 \%$ \\
\hline Blogs & 0 & $0,00 \%$ & 0 & $0,00 \%$ & 4 & $1,65 \%$ & 4 & $1,65 \%$ \\
\hline News & 0 & $0,00 \%$ & 0 & $0,00 \%$ & 4 & $1,65 \%$ & 4 & $1,65 \%$ \\
\hline Total & 45 & $18,52 \%$ & 88 & $36,21 \%$ & 110 & $45,27 \%$ & 243 & $100 \%$ \\
\hline
\end{tabular}

Fonte: Dados da pesquisa (2019).

Como pode ser visualizado na Tabela 2, a maioria das primeiras postagens é feita por "Outros usuários" (45,27\%), seguido da "Revista" $(36,21 \%)$ e do "Pesquisador autor" (18,52\%). Deste fato, pode-se inferir três proposições: 1) há nível considerável de participação e engajamento de outros atores da rede de comunicação científica nas mídias sociais que inclui o público em geral, podendo-se questionar se existe entre estes atores certo nível de interesse social pelas áreas de conhecimento da revista analisada; 2) a Scientific Data parece considerar o compartilhamento dos artigos nas mídias sociais como boa estratégia de divulgação; 3) as investidas para gerar visibilidade e promover os artigos na Web 2.0 parecem ser tímidas por parte do "Pesquisador Autor", o que reforça a ideia de que o uso dessas ferramentas ainda é, de certa maneira, estigmatizado pelos cientistas. Observação semelhante foi encontrada no estudo de Príncipe (2013), que identificou muitos pesquisadores que encaram o uso das mídias sociais como uma distração dos interesses da pesquisa.

Em relação ao percentual de primeiras menções feitas pela própria Scientific Data $(36,21 \%)$, é oportuno discutir a pertinência da divulgação institucional das atividades acadêmicas. Ao investigar a divulgação científica feita nas 50 universidades mais bem colocadas no Ranking Universitário Folha de 2015 (RUF 2015), Queiroz e Becker (2016, p. 194) perceberam “que apenas 15 mantém plataformas específicas para divulgação científica e [...] que as demais universidades tratam o tema de forma marginal." Para os autores, o processo de divulgação do conhecimento científico "poderia ser benefíciado com o investimento nas mídias sociais [...] que, além de ser mais barato para as universidades, acelera o processo de publicação" (QUEIROZ; BECKER, 2016, 
p. 195). Sob esta mesma ótica, defende-se a necessidade das organizações relacionadas às atividades de ciência e tecnologia refletirem sobre seus papéis no planejamento e divulgação de conteúdos científicos em mídias sociais.

Apesar de se reconhecer o dever do próprio cientista na divulgação de suas pesquisas, depreende-se pelos indicadores analisados que eles não são os únicos e nem os mais importantes divulgadores científicos na atualidade. Principalmente em contextos em que as pesquisas são financiadas com dinheiro público, como o brasileiro, considera-se primordial a atuação das instituições para dar visibilidade aos resultados encontrados, engajando a sociedade com temas relacionados à pesquisa. Nesse sentido, o uso de ferramentas da Web 2.0, como as mídias sociais, pode contribuir sobremaneira para "prestação de contas adicional às publicações em periódicos e participações em congressos" (QUEIROZ; BECKER, 2016, p. 195). Mas, como e se as organizações (universidades, bibliotecas, laboratórios, setores dedicados à comunicação social etc.) devem participar dos processos de divulgação das produções acadêmicas em mídias sociais precisa ser investigado e posto em pauta.

\subsection{Visibilidade nas mídias sociais e contagem de citações}

A partir dos dados coletados na Amostra 2, foi possível relacionar a visibilidade nas mídias sociais dos dez artigos mais citados de cada ano (totalizando 40 artigos analisados) e o possível incremento na contagem de citações dos artigos da Scientific Data. Para tanto, as publicações foram separadas por data de publicação, considerando os últimos quatro anos (2015 a 2018) e ordenadas pelo maior número de citações recuperadas pela Altmetric. Dessa amostra percebeuse que os dez artigos mais citados em cada ano foram mencionados em mídias sociais pelo menos cinco vezes e baixados por leitores da biblioteca do Mendeley no mínimo 20 vezes. Esses artigos explicitam relações moderadamente fortes entre a contagem de citações e a contagem de downloads da biblioteca do Mendeley (Figura 3).

Figura 3 - Relação entre menções e citações dos artigos publicados na Scientific Data (2015-2018). 

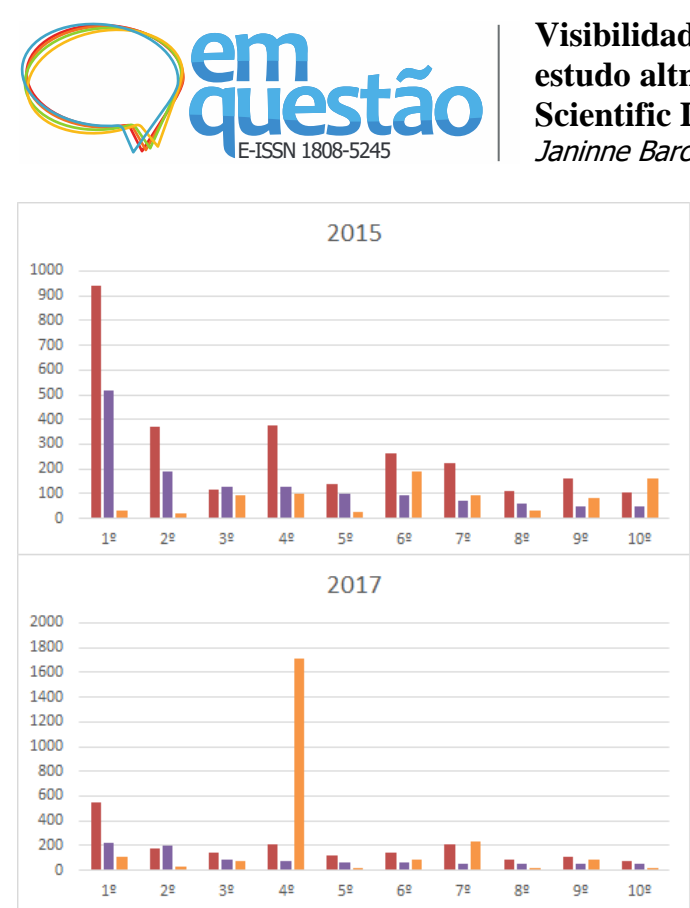

Fonte: Dados da pesquisa (2019).

Janinne Barcelos e João de Melo Maricato

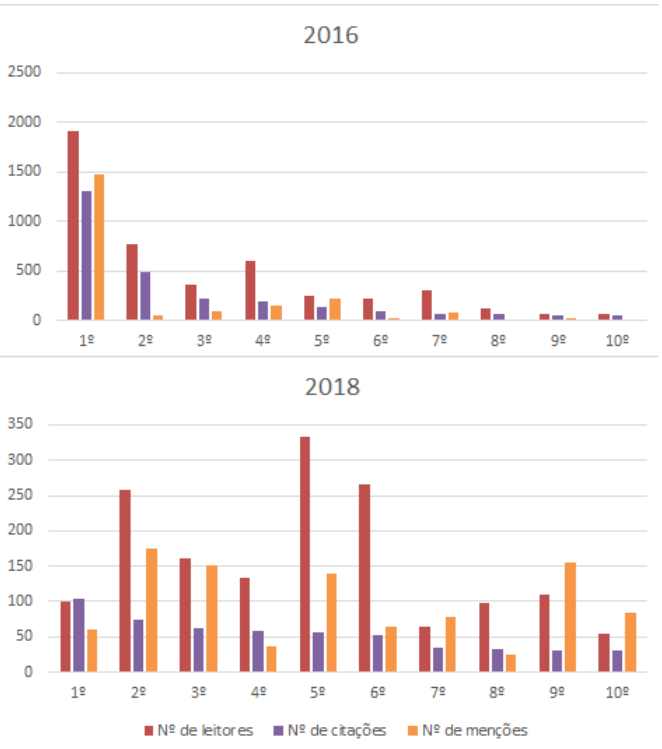

Os dez artigos mais citados apresentam correlações diferentes a cada ano. Estatisticamente falando, observa-se que os dez artigos de cada um dos anos possuem Correlação de Pearson que vão entre negativa baixa e positiva muito alta entre Leitores (Mendeley) e Citações (Dimensions) e entre Citações (Dimensions) e Menções (Mídias).

As correlações entre Leitores (Mendeley) e Citações (Dimensions) ao longo dos anos são predominantemente fortes: 2015 (0,96 - positiva muito forte); 2016 (0,98 - positiva muito forte); 2017 (0,77 - forte); 2018 (0,3 positiva fraca). Por outro lado, as correlações entre Citações (Dimensions) e Menções (Mídias) são menos estáveis, tendendo a ser mais fraca: 2015 (-0,42 negativa moderada); 2016 (0,94 - positiva forte); 2017 (-0,09 - negativa bem fraca); 2018 (0,09 - positiva bem fraca).

De maneira geral, é possível notar que existe certa relação entre as curvas de leitores do Mendeley, Citações (Dimensions) e Menções (Mídias), não sendo possível indicar uma relação de causa e efeito entre os indicadores. Observação semelhante foi verificada nos estudos de Thelwall et al. (2013, p. 4, tradução nossa), salienta que:

uma correlação não implica causalidade, assim com a falta de correlação não implica inutilidade, mas uma correlação sugere relação com o impacto da citação ou pelo menos com alguns dos fatores que causam o impacto da citação. 
Ao explorar as relações entre o impacto acadêmico e mídias sociais, Priem, Piwowar e Hemminger (2012) destacam que os indicadores altmétricos e a análise de citações mensuram tipos de impacto diferentes, mas que se relacionam.

\section{Considerações finais}

Tradicionalmente, a comunicação científica é um processo que começa com uma intuição de pesquisa, vira uma publicação formal e, por meio da revisão pelos pares, é finalmente aceita como parte do conhecimento científico. Ininterrupto, esse fluxo faz despertar novos questionamentos, a partir dos quais pesquisadores criam referências e citações entre pesquisas anteriores e atuais. Com base nesta lógica, os tradicionais estudos métricos da informação têm entendido que parte do sistema de premiação científica está apoiada no pressuposto de que quanto mais citações uma pesquisa recebe, mais valor ela tem, e, portanto, que os pesquisadores mais citados tendem a ter maior prestígio.

Acontece que, com a atualização contínua das tecnologias de comunicação e informação e, especialmente, com a chegada das mídias sociais, a produção científica e seus outputs podem ganhar visibilidade e serem reconhecidos de muitas outras maneiras - não apenas por citações formais. Livros, artigos e periódicos, por exemplo, podem ser mencionados no Twitter, curtidos no Facebook, compartilhados no Weibo, comentados em blogs, sites de notícias, etc. A partir deste estudo, foi possível constatar que o uso das mídias sociais tem grande potencial para abrir novas arenas de discussão e cultivar conversas sobre a publicação acadêmica.

No universo analisado (1.036 artigos), o Twitter, o Facebook e os Blogs ocupam lugar de destaque entre as mídias mais utilizadas por pesquisadores e público em geral, podendo indicar certa preferência e popularidade dessas redes na busca por visibilidade e oportunidades de engajamento entre os usuários. Vale ressaltar que o Twitter representou mais de $93 \%$ do número de menções sobre os artigos da revista Scientific Data. O que faz emergir novos questionamentos como: quais os motivos da concentração das menções em poucas mídias e ausência em outras? As menções públicas concentradas em poucas mídias sociais se repetem em outras temáticas, revistas ou áreas do 
conhecimento? Portanto, fica clara a necessidade de maior reflexão sobre o papel das diferentes mídias e suas possibilidades de afetar de maneira mais ampla e eficiente os diferentes públicos.

Com relação aos tipos de audiência e engajamento público das menções em mídias sociais na revista Scientific Data, identificou-se que a autoria dos primeiros posts é feita, em sua maioria, pelo que chamamos de "Outros usuários", e não pelos próprios autores dos artigos. Mais de $41 \%$ das postagens em blogs, sites de notícias, Facebook e Twitter foram feitas por "Outros usuários", seguido das Revistas (cerca de 33\%). O pesquisador autor só registra engajamento no Twitter (18,52\%). Contrariando uma das hipóteses iniciais, estes indicadores demonstraram que grande parte das menções não são iniciativas do próprio pesquisador para promover suas publicações.

Deste fato pode-se inferir que há indícios de reverberação da pesquisa (visibilidade), de envolvimento e de engajamento por parte de grupos de "Outros usuários" com os próprios artigos ou outras formas de divulgação científica. Apesar disso, é necessário a realização de outras pesquisas que respondam às seguintes questões: quem são esses atores? qual o papel das instituições (universidades, bibliotecas, laboratórios, assessorias de comunicação) na divulgação de produtos acadêmicos em mídias sociais? Qual seria também o papel das revistas? E como o pesquisador deve dar visibilidade aos seus outputs acadêmicos em mídias sociais? A "automenção" seria uma atividade aceita pela academia? Haveria algum limite para as automenções, como acontece com as autocitações?

No que diz respeito a visibilidade dos artigos na Web 2.0 e o possível aumento no número de citações, foram encontradas relações moderadas entre as menções em mídias sociais, os downloads da biblioteca do Mendeley e os maiores indicadores de citações. No entanto, admite-se que tais observações também podem ser o resultado de vários fatores distintos ou sobrepostos, que a metodologia utilizada falha em distinguir. Dessa forma, seria precipitado concluir que número de citações de um artigo pode ser incrementado apenas com postagens sobre ele nas mídias sociais. Contudo, há de se observar que por menor que seja - existe uma relação que precisa ser melhor investigada em estudos futuros. 
Deste cenário, conclui-se que o uso das mídias sociais está, cada dia mais, afetando o fluxo de comunicação das pesquisas. Seja por meio de comentários no Facebook, Twitter e Reddit, ou através de serviços de revisão por pares como o F1000, a Web 2.0 tem demonstrado grande capacidade para impactar na visibilidade e nas oportunidades de comunicação e divulgação dos estudos - "com uma vantagem secundária: expor e corrigir processos acadêmicos uma vez escondidos e efêmeros" (PRIEM; PIWOWAR; HEMMINGER, 2012, n.p.).

Certamente, as postagens em torno das produções científicas estão longe de serem adotadas como parte das métricas de avaliação diária de artigos e outras publicações, mas não podemos negar o valor de se saber o que é interessante para a sociedade. Um sistema de comunicação e divulgação científica que apoia os objetivos de desenvolvimento nacional deve preocupar-se em facilitar e incentivar promoção de comunidades de pesquisa e conhecimento partilhado, promovendo colaboração e estando aberto para mudança de percursos.

\section{Compartilhamento de dados}

Por entender que o compartilhamento dos dados de pesquisa permite que outros pesquisadores possam explorá-los para confrontar resultados e confirmar novas hipóteses, os dados brutos deste estudo estão abertamente compartilhados no repositório Zenodo e podem ser acessados no sítio: https://doi.org/10.5281/zenodo.3627029.

\section{Agradecimentos}

Os autores gostariam de agradecer à plataforma Altmetric, ao acadêmico de pósgraduação da Faculdade de Ciência da Informação da Universidade de Brasília (FCI/UnB), Diego José Macêdo, por apoiar o planejamento e execução da coleta de dados e ao Dr. André Luiz Appel, do Instituto Brasileiro de Informação em Ciência e Tecnologia (Ibict), por sua valiosa contribuição com ideias e ferramentas para disponibilização dos dados abertos de pesquisa.

\section{Referências}


ALPERIN, J. P. Ask not what Altmetrics can do for you, but what altmetrics can do for developing countries. 2013. Disponível em: http://www.asis.org/Bulletin/Apr13/AprMay13_Alperin.html. Acesso em: 30 out. 2019.

ALTMETRIC. Sources of attention: Altmetric track a unique range of online sources to capture the conversations relating to research outputs. London: Altmetrics, 2019. Disponível em: https://www.altmetric.com/about-ourdata/our-sources/. Acesso em: 11 dez. 2019.

ARAÚJO, R. F. Marketing científico digital e métricas alternativas para periódicos: da visibilidade ao engajamento. Perspectivas em Ciência da Informação, Belo Horizonte, v. 20, n. 3, p. 67-84, jul./set. 2015.

BARATA, G. F. Germana Barata fala sobre potencial das mídias sociais para a divulgação científica. Rio de Janeiro, Fiocruz, 2016. 1 vídeo (2 min). Publicado pelo canal Fiocruz. Disponível em:

https://www.youtube.com/watch?v=qOrKujqe9VY. Acesso em: 28 mar. 2019.

BARCELOS, J.; MACÊDO, D. J.; MARICATO, J. M. Altmetrics in Altmetric platform: an interview with Stacy Konkiel. Revista Ibero-Americana de Ciência da Informação, Brasília, v. 13, n. 1, p. 452-474, 2020.

BARCELOS, J.; MARICATO, J. M. Menções sobre a produção acadêmica nas mídias sociais: estudo altmétrico de visibilidade e engajamento público com artigos da Scientometrics. In: ENCONTRO NACIONAL DE PESQUISA EM CIÊNCIA DA INFORMAÇÃO, 18., 2017, Marília. Anais [...]. Marília: ANCIB, 2017.

BIK, H. M.; GOLDSTEIN, M. C. An Introduction to Social Media for Scientists. PLoS Biology, v. 11, n. 4, 2013.

BOMFÁ, C. R. J. et. al. Marketing científico eletrônico: um novo conceito voltado para periódicos eletrônicos. Estudos em Comunicação, Covilhã, v. 5, 2009.

CUNHA, M. B.; CAVALCANTI, C. R. O. Dicionário de Biblioteconomia e Arquivologia. Brasília: Briquet de Lemos, 2008.

ERFANMANESH, M.; ALPERIN, J. P. Twitter audiences overlap in informetrics research. In: ALTMETRICS CONFERENCE, 2017, Toronto. Anais [...]. Toronto: Altmetrics, 2017.

FILIPPO, D.; SANZ-CASADO, E. Bibliometric and Altmetric Analysis of Three Social Science Disciplines. Frontiers In Research Metrics And Analytics, v. 3, Dec. 2018. 
HUBERMAN, B. A.; ROMERO, D. M.; WU, F. Social networks that matter: Twitter under the microscope. arXiv, 0812.1045v1, 2008. Disponível em: https://arxiv.org/abs/0812.1045. Acesso: 26 fev. 2019.

IAMARINO, A. Métricas alternativas: uma introdução para autores e avaliadores. In: VOGT, C.; GOMES, M.; MUNIZ, R. (ed.). Comciência e divulgação científica. Campinas: BCCL/ UNICAMP, 2018. p. 61-72.

KEMP, S. Global digital report 2019. Disponível em: https://digitalreport.wearesocial.com/. Acesso em: 2 nov. 2019.

KOLAHI, J. et al. Altmetric analysis of the contemporary scientific literature in Endodontology. International Endodontic Journal, v. 53, 2020.

LEE, J. M. How to use Twitter to further your research career. Nature, 2019. Disponível em: https://www.nature.com/articles/d41586-019-00535-w. Acesso em: 12 out. 2019.

LEWENSTEIN, B. Models of public communication of science \& technology. Public Understanding of Science, Ithaca, 2003.

MASSARANI, L. Comunicação da ciência e apropriação social da ciência: algumas reflexões sobre o caso do Brasil. Uni-pluriversidad, Medelín, v. 12, n. 3, p. 92-100, 2012.

MIURA, J. Os desafios para construção de uma ciência 2.0. 2012. Dissertação (Mestrado em Multimédia) - Faculdade de Engenharia, Universidade do Porto, Porto, 2012.

MUELLER, S. A ciência, o sistema de comunicação científica e a literatura científica. In: CAMPELLO, B. S.; CENDON, B. V.; KREMER, J. M. (org.). Fontes de informação para pesquisadores e profissionais. Belo Horizonte: UFMG, 2000.

NASSI-CALÓ, L. Estudo analisa o uso de redes sociais na avaliação do impacto científico. SciELO em Perspectiva, 2015. Disponível em:

http://blog.scielo.org/blog/2015/03/13/estudo-analisa-o-uso-de-redes-sociais-naavaliacao-do-impacto-cientifico/\#.WYuns4jyvIU. Acesso em: 20 nov. 2019.

NATIONAL INFORMATION STANDARDS ORGANIZATION. Outputs of the NISO Alternative Assessment Metrics Project. Baltimore: NISO, 2016.

OLIVEIRA, F. D. Jornalismo científico. São Paulo: Contexto, 2002.

OLIVEIRA, F. T.; GRÁCIO, M. C. C. Visibilidade dos pesquisadores no periódico Scientometrics a partir da perspectiva brasileira: um estudo de cocitação. Em Questão, Porto Alegre, v. 18, n. 3, p. 99-113, dez. 2012. 
PRIEM, J.; HEMMINGER, B. M.; Scientometrics 2.0: Toward new metrics of scholarly impact on the social Web. First Monday, Chicago, v. 15, n. 7, 2010.

PRIEM, J.; PIWOWAR, H. A.; HEMMINGER, B. M. Altmetrics in the wild: using social media to explore scholarly impact. 2012. Disponível em: https://arxiv.org/abs/1203.4745. Acesso em: 20 jan. 2019.

PRÍNCIPE, E. Comunicação científica e redes sociais. In: ALBAGLI, Sarita (org.). Fronteiras da Ciência da Informação. Brasília: IBICT, 2013.

QUEIROZ, G. B. R.; BECKER, V. Jornalismo e divulgação científicos nas universidades brasileiras: análise de estratégias para facilitar o acesso à C\&T. Brazilian journalism research, Brasília, v. 12, n. 3, p. 178-197, 2016.

ROEMER, R. C.; BORCHARDT, R. Altmetrics. Washington: American Library Association, 2015.

THELWALL, M. et al. Do Altmetrics Work? Twitter and Ten Other Social Web Services. PloS One, v. 8, n. 5, May 2013.

THOMPSON, J. B. A nova visibilidade. MATRIZes, São Paulo, n. 2, p. 15-38, abr. 2008.

WILCOX, C. Social Media for Scientists Part 1: It's Our Job. Scientific American Blog, 2011. Disponível em: https://blogs.scientificamerican.com/science-sushi/social-media-for-scientistspart-1-it-8217-s-our-job/. Acesso em: 18 fev. 2019.

ZIMAN, J. M. Conhecimento público. Belo Horizonte: Itatiaia, 1979.

\title{
Visibility and public engagement on the web 2.0: an altmetric study based on articles published in Scientific Data
}

\begin{abstract}
Web 2.0 has caused an impact on scientific communication. The social media has been increasingly used to share scientific products, with different dynamics of visibility and public engagement. In this context, this paper seeks to understand aspects of visibility and engagement on Web 2.0, based on articles published by Scientific Data, between 2014 and 2019, using altmetrics methods and techniques. In this way, it identifies and analyzes medias in which those papers received attention, such as the users who first posted the paper on social media and relations between mentions and the possible increase in the citations count. It was found that Twitter was the most used media for the dissemination of papers; that researchers are not the first ones to mention their papers in the analyzed medias; and, that there is not a cause/effect relation between citations and mentions indicators. Relevant aspects were shown for the
\end{abstract}


comprehension of visibility and public engagement with papers on social media, helping as well to understand the dynamics and characteristics related to altmetrics indicators.

Keywords: Visibility. Public engagement. Social media. Altmetrics.

Recebido: $25 / 01 / 2020$

Aceito: 22/05/2020

\section{Como citar}

BARCELOS, Janine; MARICATO, João de Melo. Visibilidade e engajamento público na web 2.0: um estudo altmétrico a partir dos artigos publicados na Scientific Data. Em Questão, Porto Alegre, v.27, n. 1, p. 263-285, 2021. Doi: http://dx.doi.org/10.19132/1808-5245271.263-285

11 “O marketing científico pode ser considerado, de uma maneira geral, uma modalidade de marketing que auxilia a alavancar o crescimento do mercado de produtos científicos [...]. Assim, fala-se da utilização do marketing para consolidar, vender e projetar uma boa imagem da ciência e seus produtos (empresas, cientistas e instituições), e assim estimular a confiança e o investimento em pesquisas" (ARAÚJO, 2015, p. 71).

${ }^{2}$ Após a verificação na Altmetric, os periódicos que tiveram maior quantidade de menções foram, em ordem decrescente: Scientific Data, Information (33648), Communication \& Society (19509), Scientometrics (18536) e Journal of Chemical Information \& Modeling (17450).

${ }^{3}$ Criado em 2005, o Reddit é uma comunidade de fóruns onde os usuários podem interagir enviando links para conteúdo externo à comunidade, promovendo votações sobre quais histórias e discussões são mais importantes.

${ }^{4}$ Sites do tipo "Perguntas e Respostas". 